\title{
Irradiation Performance of AGR-1 High Temperature Reactor Fuel
}

Paul A. Demkowicz ${ }^{1, *}$, John D. Hunn ${ }^{2}$, Scott A. Ploger ${ }^{1}$, Robert N. Morris ${ }^{2}$, Charles A. Baldwin ${ }^{2}$, Jason M. Harp $^{l}$, Philip L. Winston ${ }^{1}$, Tyler J. Gerczak ${ }^{2}$, Isabella J. van Rooyen ${ }^{l}$, Fred C. Montgomery ${ }^{2}$, Chinthaka M. Silva ${ }^{2}$

${ }^{1}$ Idaho National Laboratory

P.O. Box 1625, Idaho Falls ID, 83415-6188, USA

phone: +001-208-5263846, paul.demkowicz@inl.gov

${ }^{2}$ Oak Ridge National Laboratory

P.O. Box 2008, Oak Ridge TN, 37831-6093, USA

* Corresponding author 


\section{INTRODUCTION}

The first in a series of tristructural isotropic (TRISO) coated particle fuel irradiation experiments, initiated as part of the US Advanced Gas Reactor (AGR) fuel development and qualification effort (Petti et al., 2010), completed 620 effective full power days in the Advanced Test Reactor at the Idaho National Laboratory (INL). The AGR-1 experiment contained 72 fuel compacts, each containing approximately 4,100 TRISO particles with kernels comprised of a heterogeneous mixture of uranium oxide and uranium carbide (termed UCO) (Maki 2009). The irradiation experiment was a major success, achieving a peak compact-average burnup of $19.6 \%$ fissions per initial heavy metal atom (FIMA) with zero TRISO coating failures (i.e., failure of all three dense coating layers) detected during the irradiation based on monitoring of fission gas release from the fuel (Grover et al., 2010).

Post-irradiation examination (PIE) of the AGR-1 experiment commenced in 2010 at INL and Oak Ridge National Laboratory (ORNL). The primary objectives of the AGR-1 PIE are to analyze the fuel and irradiation capsule components to verify fuel performance in the reactor and perform post-irradiation high temperature safety tests to assess fuel performance during postulated reactor accident scenarios. Fuel performance assessment focuses in particular on the behavior of the kernel and coating layers and the retention of fission products by the particles and fuel compacts, a key metric since fission product retention by TRISO fuel is an important component of the reactor safety basis. Ultimately the goal is a better understanding of the causes of coating degradation and failure, the role that fission products may play in these, and the transport behavior of fission products in fuel particles and compacts, both when coatings perform as designed and when they are damaged by irradiation or elevated temperature.

\section{EXPERIMENTAL}

The AGR-1 PIE consists of a diverse set of analyses performed on the fuel compacts, particles, and the irradiation capsules. Due to the unique nature of coated particle fuel, specialized equipment has been developed at both INL and ORNL for performing some of these tests and analyses. The experimental results presented and discussed in this paper are focused on assessing the performance of the fuel during the irradiation. In addition, high temperature safety tests have been performed on the AGR-1 fuel at INL and ORNL in order to explore the fuel performance under the conditions that may exist in the reactor core during a depressurized loss of forced cooling accident (Morris et al., 2014).

\subsection{AGR-1 fuel and irradiation experiment}

The AGR-1 UCO fuel kernels were fabricated by Babcock and Wilcox Nuclear Operations Group (Barnes et al., 2008). Kernels were nominally $350 \mu \mathrm{m}$ in diameter and ${ }^{235} \mathrm{U}$ enrichment was $19.74 \%$. The TRISO coatings were applied at ORNL. Nominal coating thicknesses were $100 \mu \mathrm{m}$ for the porous carbon buffer, $40 \mu \mathrm{m}$ for the inner pyrolytic carbon (IPyC) layer, $35 \mu \mathrm{m}$ for the SiC layer, and $40 \mu \mathrm{m}$ for the outer pyrolytic carbon (OPyC) layer. The coated particles were formed into right cylindrical compacts at ORNL that were nominally $12.4 \mathrm{~mm}$ in diameter and $25.1 \mathrm{~mm}$ in length. Compacts contained an average of 4126-4150 particles with a packing fraction of approximately $37 \%$ (Phillips et al., 2010). A baseline fuel and three different fuel variants were fabricated. Fabrication of each variant involved modification of the deposition conditions and properties of either the inner pyrolytic carbon (IPyC) or SiC layer relative to the Baseline in order to explore the effect of various coating properties on irradiation performance (Hunn et al., 2007). For Variant 1, the IPyC coating layer conditions were varied to provide a slightly lower anisotropy and density. For Variant 3 , the $\mathrm{SiC}$ layer deposition conditions were varied to provide a finer grain microstructure relative to the Baseline fuel. Fabrication of the different fuel types also resulted in minor differences in other average properties (including coating thickness, number of particles per compact, packing fraction, and defect populations) (Hunn et al., 2012). Due to time limitations, PIE did not include extensive investigation of AGR-1 Variant 2 fuel.

The irradiation experiment consisted of six separate capsules, each with independent sweep gas flow and temperature monitoring and control. Each capsule contained 12 fuel compacts of a single fuel type retained in a graphite fuel holder in three stacks oriented in a triangular array (Fig. 1), with each stack containing four compacts (Grover et al., 2010). Each compact has a unique identifier in the format X-Y-Z that denotes the original position in the experiment: $\mathrm{X}$ indicates the capsule, $\mathrm{Y}$ indicates the axial level within the capsule, and $\mathrm{Z}$ indicates the stack. Compact 6-1-1 was irradiated in Capsule 6, Level 1 (first level at the bottom of the capsule), Stack 1. 

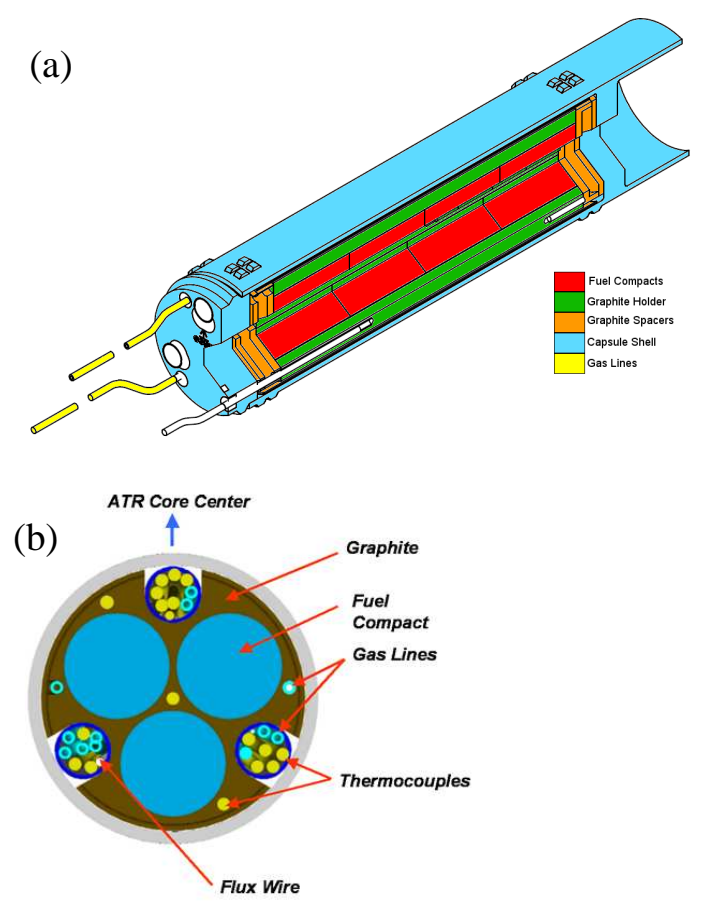

Fig. 1. Cutaway diagram of an AGR-1 capsule showing the key components (a) and cross-sectional view of a capsule (b).

The irradiation was performed from December 2006 to November 2009 for a total of 620 effective full power days. The calculated compact average burnup ranged from 11.3 to $19.6 \%$ FIMA, and compact average fast neutron fluence ranged from to 2.17 to $4.30 \times 10^{25} \mathrm{n} / \mathrm{m}^{2}$. The time-average, volume-average compact temperatures were $955-1136^{\circ} \mathrm{C}$ and the time-average maximum compact temperatures were $1069-1197^{\circ} \mathrm{C}$. Based on the low fission gas release-to-birth ratios in all of the capsules, there were zero TRISO-coating failures during the irradiation out of a total of approximately $2.98 \times 10^{5}$ in the experiment (Grover et al., 2010).

\subsection{Analysis of metallic fission product release}

The release of metallic fission products from the fuel during irradiation was assessed in several ways during post-irradiation examination, as briefly summarized here. In all cases, the measured inventories of fission products were decay-corrected to the end of the AGR-1 irradiation plus 1 day (7 November 2009, 12:00 GMT) and compared to the predicted inventory, based on physics simulations of the AGR-1 irradiation (Sterbentz, 2013), to convert the measured value to a fractional inventory. Table 1 lists the types of analyses performed and summarizes the key information pertaining to fission product release from the fuel that each data set provides. 
Table 1. Post-irradiation analysis of fuel particles, compacts, and capsule components and the key information provided on fission product release.

\begin{tabular}{ll}
\hline \multicolumn{1}{c}{ Analysis } & $\begin{array}{c}\text { Key information pertaining to } \\
\text { fission product release }\end{array}$ \\
\hline $\begin{array}{l}\text { Capsule } \\
\text { components }\end{array}$ & $\begin{array}{l}\text { Cumulative inventory of fission } \\
\text { products released from all fuel } \\
\text { compacts in a capsule during } \\
\text { irradiation }\end{array}$ \\
$\begin{array}{l}\text { Fuel compact } \\
\text { gamma scanning }\end{array}$ & $\begin{array}{l}\text { Retained inventory of fission } \\
\text { products in each individual fuel } \\
\text { compact }\end{array}$ \\
$\begin{array}{l}\text { Deconsolidation- } \\
\text { leach-burn-leach }\end{array}$ & $\begin{array}{l}\text { Inventory of fission products } \\
\text { retained in the compacts outside of } \\
\text { the SiC layers }\end{array}$ \\
$\begin{array}{l}\text { Particle gamma } \\
\text { counting }\end{array}$ & $\begin{array}{l}\text { Retained inventory of fission } \\
\text { products in the particles }\end{array}$ \\
\hline
\end{tabular}

\subsubsection{Analysis of irradiation capsule components for deposited fission products}

The major components of the irradiation capsules-including the metal shells and structural components, the graphite fuel holders, and graphite spacers at the ends of the capsules-were analyzed at INL to determine the cumulative inventories of fission products released from the compacts during the irradiation. As there were 12 compacts in each irradiation capsule, the data provide information on the total inventory of fission products released from all 12 fuel compacts; release from each compact cannot be derived from these data.

The metal capsule shells were leached in acid to remove deposits. Analysis of the leach solutions included gamma spectrometry for gamma-emitting fission products, Sr separation and gas flow proportional counting for ${ }^{90} \mathrm{Sr}$, and inductively coupled plasma mass spectrometry (ICP-MS) for actinides and other non-gamma-emitting fission products. The graphite holders were gamma counted to determine the inventory of gamma-emitting fission products, and then crushed, oxidized, and leached and the solutions analyzed as described above. The graphite spacers at the axial ends of each capsule were gamma counted. Details of the experimental procedures and the inventories of specific isotopes on the various components have been provided elsewhere (Demkowicz et al., 2013; Harp et al., 2012).

\subsubsection{Gamma scanning of individual fuel compacts}

Fifty-six of the 72 AGR-1 compacts were individually gamma scanned at INL with sufficiently long counting times to quantify ${ }^{110 \mathrm{~m}} \mathrm{Ag}$ inventory (Harp, 2013). The experimental apparatus consists of a high-purity germanium detector with a Compton suppression system, and a rectangular collimator with a 2.5-mm opening. Each compact was counted in 2.5-mm axial "slices". The gamma scanning system was calibrated so that the total activity in a compact could be measured by adding the measured activity from all scans corresponding to a single compact. Interference from ${ }^{137} \mathrm{Cs}$ prevented the use of the primary ${ }^{110 \mathrm{~m}} \mathrm{Ag}$ gamma-ray necessitating the use of the secondand third-most intense gamma-ray lines for activity determination. The experimental setup for gamma scanning the compacts for ${ }^{110 \mathrm{~m}} \mathrm{Ag}$ was very similar to that described by Harp et al. (2014). By comparing measured inventories with the predicted values, the data provide information on the level of silver retention in each compact analyzed.

\subsubsection{Deconsolidation and leach-burn-leach analysis of fuel compacts}

A total of nine AGR-1 compacts were electrolytically deconsolidated in the as-irradiated state and leachburn-leach analysis was performed at both INL and ORNL. The deconsolidation-leach-burn-leach (DLBL) analysis effectively measures the total inventory of fission products located in the compact outside of the $\mathrm{SiC}$ layer (i.e., it includes the contributions from both the OPyC and matrix), provided that no particles with a failed $\mathrm{SiC}$ layer are present (in this article, "SiC failure" refers to loss of integrity of the SiC layer, with at least one pyrocarbon layer remaining intact, and is distinct from complete TRISO-coating failure). It is therefore a measure of fission products that (a) are retained within the compact outside of the SiC layers, and (b) generated from uranium contamination in the compact matrix or $\mathrm{OPyC}$ and retained within the compact during irradiation. As the level of uranium contamination in the AGR-1 compacts was generally very low (average uranium contamination fractions were less than $4 \times 10^{-7}$ for all AGR-1 fuel types), the inventory measured from DLBL is typically 
dominated by release from the particles. In some cases, if measured values are very low (as is often the case with cesium, where release through intact $\mathrm{SiC}$ is found to be extremely low), then hot cell contamination can constitute a significant contribution to the total measured values. The nine AGR-1 compacts analyzed are listed in Table 2 with the fuel type and selected irradiation properties.

Table 2. Irradiated AGR-1 fuel compacts used for DLBL analysis and particle gamma counting.

\begin{tabular}{|c|c|c|c|c|c|}
\hline 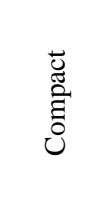 & 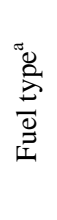 & 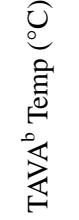 &  &  & 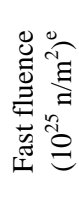 \\
\hline $6-3-2$ & B & 1070 & 1144 & 11.4 & 2.55 \\
\hline $6-1-1$ & B & 1111 & 1197 & 15.3 & 2.43 \\
\hline $3-2-1$ & $\mathrm{~B}$ & 1051 & 1143 & 19.1 & 4.21 \\
\hline $5-2-1$ & V1 & 1057 & 1140 & 17.4 & 3.71 \\
\hline $5-2-3$ & V1 & 1059 & 1141 & 17.4 & 3.77 \\
\hline $5-3-1$ & V1 & 1040 & 1122 & 16.7 & 3.60 \\
\hline $4-4-2$ & V3 & 1024 & 1139 & 16.6 & 3.59 \\
\hline $4-1-1$ & V3 & 1072 & 1182 & 19.4 & 4.13 \\
\hline $1-3-1$ & V3 & 1092 & 1166 & 15.3 & 3.22 \\
\hline \multicolumn{6}{|c|}{${ }^{\mathrm{a}} \mathrm{B}=$ Baseline; $\mathrm{V} 1=$ Variant $1 ; \mathrm{V} 3=$ Variant 3} \\
\hline \multicolumn{6}{|c|}{${ }^{\mathrm{b}}$ Time average, volume average temperature } \\
\hline \multicolumn{6}{|c|}{ c Hawkes, 2012} \\
\hline \multicolumn{6}{|c|}{$\mathrm{d}$ Time average maximum temperature } \\
\hline e Sterber & & & & & \\
\hline
\end{tabular}

Compacts were deconsolidated in a glass tube with the bottom $\sim 1 \mathrm{~mm}$ submerged in concentrated nitric acid. A platinum-rhodium wire was placed on the top of the compact (the anode) and a second electrode (the cathode) was placed into the nitric acid solution. An electric potential with a net power level of less than 10 watts was applied, resulting in electrolytic oxidation of the compact matrix, liberating the particles as the reaction proceeded. The loose particles and deconsolidated matrix debris were collected in a Soxhlet thimble for subsequent processing.

At the completion of the deconsolidation step, the thimble was transferred into a Soxhlet extraction apparatus and two 24-hour extraction cycles were performed using fresh concentrated nitric acid solution for each cycle. The leachate solution from each of the cycles was assayed for fission products and actinides. The entire thimble was then transferred to an oven where a burn step was performed for 72 hours at $750^{\circ} \mathrm{C}$ in air. This oxidized all exposed carbon, including any remaining matrix debris, the outer pyrolytic carbon layer, and the inner pyrolytic carbon and buffer layers of any particles with fractures or holes in the SiC layer. The thimble was then transferred back to the Soxhlet extractor and two more 24-hour leach cycles were performed, with each solution again assayed for actinides and fission products. If any particles had failed $\mathrm{SiC}$, the post-burn leach steps dissolved the kernel exposed by the prior removal of the carbon layers during the burn step. Thus, the post-burn leach data can be used to determine the number of particles with failed $\mathrm{SiC}$ that were present based on the measured inventory of uranium in the solutions (a single irradiated AGR-1 kernel contains approximately $0.18 \mathrm{mg}$ of uranium).

Analysis of the leach solutions included gamma spectrometry, ICP-MS, and Sr separation and beta counting for ${ }^{90} \mathrm{Sr}$. Additional details of the AGR-1 DLBL experiments have been presented by Baldwin et al. (2014) and Demkowicz et al. (2012).

\subsubsection{Gamma counting of individual coated particles}

Individual particles were gamma counted at various stages of the DLBL process to determine the inventory of gamma-emitting fission products. Analysis of the fission product inventory present in the particles allows the relative degree of retention to be evaluated. This analysis has a twofold objective.

Individual particles with abnormally low inventories of specific fission products can be identified, and this may be indicative of a defective SiC layer, as in the case of high cesium release. While cesium diffuses with relative ease through intact pyrocarbon, it is effectively retained by intact $\mathrm{SiC}$. However, a SiC layer defect or inpile failure may allow cesium to readily escape from the particle at normal irradiation temperatures. Therefore, measurements of the relative ${ }^{137} \mathrm{Cs}$ inventory can be used to identify particles with failed SiC. Such particles can then be retained for subsequent microstructural analysis to investigate the nature of the SiC failures. 
Identification and subsequent analysis of specific particles with failed SiC layers is the topic of a separate paper (Hunn et al., 2014) and is not discussed here.

In addition to finding particles with a defective $\mathrm{SiC}$ layer, the distribution of fission product activities among a population of particles can provide information about the varying degree of release through intact SiC. This is primarily of interest for silver, which may exhibit significant release from particles (several percent or more under normal irradiation conditions) such that differences can be detected above the uncertainty of the gamma counting technique. By measuring the ${ }^{110 \mathrm{~m}} \mathrm{Ag}$ retained in the particles, specific particles with high or low release can be selected for microstructural examination that may elucidate the causes of the behavior. For example, variations in $\mathrm{SiC}$ microstructure might be correlated with the level of silver release.

Counting all of the approximately 4,100 particles in each compact is made possible by the relatively short count times required for ${ }^{137} \mathrm{Cs}$ and ${ }^{144} \mathrm{Ce}$. Other important fission products such as ${ }^{110 \mathrm{~m}} \mathrm{Ag}$ and ${ }^{154} \mathrm{Eu}$ tend to have much lower total activity in the particles (generally $<3 \times 10^{4} \mathrm{~Bq}$ for ${ }^{110 \mathrm{~m}} \mathrm{Ag}$ and $\sim 1 \times 10^{5}$ for ${ }^{154} \mathrm{Eu}$ versus $4 \times 10^{7} \mathrm{~Bq}$ for ${ }^{144} \mathrm{Ce}$ and $4 \times 10^{6} \mathrm{~Bq}$ for ${ }^{137} \mathrm{Cs}$ ) and therefore require much longer counting times (generally several hours) to obtain statistically relevant quantification. As a consequence of the longer counting times, processing of all particles would be prohibitively time consuming. Therefore a subset of particles (approximately 40-120) is counted to establish a distribution of activities for these isotopes.

Irradiated particle gamma counting was performed at both INL and ORNL. At INL, individual particles (typically 60 per compact) were manually placed in glass vials and spectra were acquired with a lithium-drifted germanium gamma spectrometer. The energy efficiency of the spectrometer system was calibrated using a $3.48 \times 10^{6} \mathrm{~Bq}{ }^{152} \mathrm{Eu}$ point source. Count times were typically varied from 1 to 12 hours in order to minimize total experimental duration while still obtaining sufficient counting data to quantify ${ }^{110 \mathrm{~m}} \mathrm{Ag}$ activity.

Gamma counting of particles at ORNL was accomplished using the Advanced Irradiated Microsphere Gamma Analyzer (Advanced-IMGA) (Baldwin et al., 2014; Hunn et al., 2014; Morris et al., 2010), an automated system developed at ORNL specifically for TRISO particle examinations. The system uses a vacuum needle with two-axis directional movements to automatically select a single particle from a vial located on a rotating carousel, reposition the particle in front of a high-purity germanium gamma detector, gamma count the particle for a predetermined time interval, place the particle into a designated receptacle vial based on specified criteria, and then repeat the process until all particles have been counted.

Subsets of particles from nine AGR-1 compacts (listed in Table 2) were gamma counted. The measured ${ }^{110 \mathrm{~m}} \mathrm{Ag}$ inventory in each particle was compared to the calculated activity in an average particle from that fuel compact to determine an estimated fraction of ${ }^{110 \mathrm{~m}} \mathrm{Ag}$ retained. To minimize the effect of particle-to-particle variation in fissile content (due to variation in kernel size, density, and stoichiometry) and burnup, the ratio of measured ${ }^{110 \mathrm{~m}} \mathrm{Ag}$ activity to the calculated ${ }^{110 \mathrm{~m}} \mathrm{Ag}$ activity was normalized using the ${ }^{137} \mathrm{Cs}$ activity, as in the following equation,

$$
\frac{A_{i}^{A g-110 m}}{A_{\text {calc }}^{A g-110 m} \times\left(\frac{A_{i}^{C s-137}}{\sum_{j=1}^{n} \frac{1}{n} A_{j}^{C s-137}}\right)}
$$

where $A_{i}^{A g-110 m}$ is the decay-corrected measured ${ }^{110 \mathrm{~m}} \mathrm{Ag}$ activity of particle $i, A_{\text {calc }}^{A g-110 \mathrm{~m}}$ is the average calculated ${ }^{110 \mathrm{~m}} \mathrm{Ag}$ activity for a single particle, $A_{i}^{C s-137}$ is the decay-corrected measured ${ }^{137} \mathrm{Cs}$ activity for particle $i$, and $n$ is the total number of particles counted.

\subsection{Microanalysis}

Microanalysis of the AGR-1 fuel consisted of characterization of both sectioned compacts and individual particles. Six irradiated AGR-1 fuel compacts were sectioned axially and longitudinally and the polished crosssections were examined using optical microscopy as described by Ploger et al. (2014). Approximately 1000 particles exposed in the compact cross-sections were examined and characterized based on the kernel and coating behavior during irradiation.

In addition, individual particles taken from numerous deconsolidated fuel compacts were mounted in epoxy, ground, and polished to prepare cross-sections for examination. Several hundred such particles were successively ground and polished to expose particle cross-sections at increasing displacements into the particle. This was undertaken to better understand the morphology of irradiated kernels and coating layers in three dimensions, as 
two-dimensional cross-sections often limit complete characterization of important features. Major results of optical microscopy are discussed in this paper.

Detailed microanalysis of individually mounted irradiated particles included scanning electron microscopy (SEM) with elemental analysis including energy dispersive x-ray spectroscopy (EDS) and wavelength dispersive $\mathrm{x}$-ray spectroscopy (WDS) to examine the coating microstructure and distribution of fission products and actinides within the coating layers.

Following this characterization, selected particles were examined with more advanced techniques to further explore the coating microstructures (especially the $\mathrm{SiC}$ layer) and investigate the migration of fission products and actinides within the layers in order to better understand transport behavior. A focused ion beam (FIB) was used to prepare small specimens from the kernels and coating layers for analysis with transmission electron microscopy (TEM) and scanning transmission electron microscopy (STEM). Elemental analysis was performed on selected specimens using TEM-EDS and electron energy loss spectroscopy (EELS) in order to help identify specific elements in the coating layers, often at the nanometer scale. Finally, work has begun using atom probe tomography (APT) to further expand the existing database with information down to the atomic level.

\section{FISSION PRODUCT RELEASE}

\subsection{Experimental results}

The inventory of key fission products released from the compacts to the capsule components is summarized in Table 3. These values represent the sum of inventories measured on the various components from each capsule (detailed data for isotopic inventory found on each capsule component has been presented by Demkowicz et al., 2013). Values are presented as a fraction of the predicted inventory in the capsule (includes the contribution from all twelve compacts in each capsule).

The inventory of key fission products found outside the SiC layer in the nine compacts listed in Table 2 is given in Table 4 (based on DLBL data), where the totals include exposed fission products in the fuel compact detected by both the pre-burn and post-burn leaches. The values are presented as a fraction of the predicted inventory in the compact, and represent the inventory of fission products released from the particles but retained within the OPyC or compact matrix during irradiation. Note that in Table 3 and Table $4{ }^{134} \mathrm{Cs}$ data have been presented instead of ${ }^{137} \mathrm{Cs}$, as the ${ }^{134} \mathrm{Cs}$ measurements were found to be less subject to bias from the presence of hot cell contamination due to the much shorter half-life $\left(2.07 \mathrm{y}\right.$ for ${ }^{134} \mathrm{Cs}$ compared to $30.07 \mathrm{y}$ for $\left.{ }^{137} \mathrm{Cs}\right)$. In instances where hot-cell contamination had a minimal effect on the cesium measurements, the agreement between fractional releases calculated for ${ }^{134} \mathrm{Cs}$ and ${ }^{137} \mathrm{Cs}$ was generally very good. Similarly, although only ${ }^{154} \mathrm{Eu}$ is reported, ${ }^{155} \mathrm{Eu}$ was also measured and yielded matching results.

Table 3. Fractional inventory of fission products on the AGR-1 capsule components.

\begin{tabular}{ccccccc}
\hline Capsule \# & Fuel type & ${ }^{\mathbf{1 1 0 m}^{A g}}$ & ${ }^{\mathbf{1 4 4}} \mathbf{C e}$ & ${ }^{\mathbf{1 3 4}} \mathbf{C s}$ & ${ }^{\mathbf{1 5 4}} \mathbf{E u}$ & ${ }^{\mathbf{9 0}} \mathbf{S r}$ \\
\hline 6 & Baseline & $3.8 \mathrm{E}-1$ & $9.7 \mathrm{E}-6$ & $1.3 \mathrm{E}-5$ & $4.6 \mathrm{E}-4$ & $3.1 \mathrm{E}-6$ \\
5 & Variant 1 & $2.3 \mathrm{E}-1$ & $<2 \mathrm{E}-6$ & $1.2 \mathrm{E}-5$ & $1.4 \mathrm{E}-4$ & $7.1 \mathrm{E}-6$ \\
4 & Variant 3 & $1.2 \mathrm{E}-1$ & $<4 \mathrm{E}-6$ & $<3 \mathrm{E}-6$ & $1.3 \mathrm{E}-4$ & $9.7 \mathrm{E}-6$ \\
3 & Baseline & $1.2 \mathrm{E}-2$ & $<4 \mathrm{E}-6$ & $<3 \mathrm{E}-6$ & $4.3 \mathrm{E}-4$ & $2.2 \mathrm{E}-6$ \\
2 & Variant 2 & $5.5 \mathrm{E}-2$ & $<2 \mathrm{E}-6$ & $<2 \mathrm{E}-6$ & $1.6 \mathrm{E}-4$ & $8.4 \mathrm{E}-7$ \\
1 & Variant 3 & $3.6 \mathrm{E}-1$ & $<3 \mathrm{E}-6$ & $<3 \mathrm{E}-6$ & $1.3 \mathrm{E}-4$ & $2.8 \mathrm{E}-5$ \\
\hline
\end{tabular}

Note that a fraction of $2.0 \mathrm{E}-5$ corresponds to the equivalent inventory of a single particle (based on approximately 49,200 particles per capsule). 
Table 1. Fractional inventory of fission products in the DLBL solutions.

\begin{tabular}{cccccccc}
\hline Compact & ${ }^{{ }^{110 m}} \mathbf{A g}$ & ${ }^{\mathbf{1 4 4}} \mathbf{C e}$ & ${ }^{\mathbf{1 3 4}} \mathbf{C s}$ & ${ }^{154} \mathbf{E u}$ & ${ }^{{ }^{105}} \mathbf{P d}$ & ${ }^{\mathbf{9 0}} \mathbf{S r}$ & ${ }^{\mathbf{2 3 8}} \mathbf{U}$ \\
\hline $6-3-2$ & $2.2 \mathrm{E}-4$ & $1.7 \mathrm{E}-4$ & $7.3 \mathrm{E}-5$ & $5.9 \mathrm{E}-3$ & & $4.3 \mathrm{E}-4$ & $2.8 \mathrm{E}-4$ \\
$6-1-1$ & $1.7 \mathrm{E}-1$ & $6.9 \mathrm{E}-4$ & $2.1 \mathrm{E}-5$ & $1.5 \mathrm{E}-2$ & $1.1 \mathrm{E}-2$ & $5.9 \mathrm{E}-4$ & $<1 \mathrm{E}-4$ \\
$3-2-1$ & $6.6 \mathrm{E}-3$ & $<4 \mathrm{E}-6$ & $<3 \mathrm{E}-6$ & $7.4 \mathrm{E}-4$ & & $1.5 \mathrm{E}-6$ & $5.1 \mathrm{E}-6$ \\
$5-2-3$ & $3.3 \mathrm{E}-3$ & $1.5 \mathrm{E}-3$ & $4.4 \mathrm{E}-5$ & $6.0 \mathrm{E}-3$ & $3.2 \mathrm{E}-2$ & $3.1 \mathrm{E}-3$ & $6.5 \mathrm{E}-5$ \\
$5-2-1$ & $3.9 \mathrm{E}-3$ & $1.6 \mathrm{E}-3$ & $4.8 \mathrm{E}-5$ & $5.8 \mathrm{E}-3$ & $3.0 \mathrm{E}-2$ & $1.9 \mathrm{E}-3$ & $8.2 \mathrm{E}-5$ \\
$5-3-1$ & $9.4 \mathrm{E}-3$ & $3.5 \mathrm{E}-4$ & $2.5 \mathrm{E}-6$ & $1.2 \mathrm{E}-3$ & $6.3 \mathrm{E}-3$ & $1.9 \mathrm{E}-4$ & $2.4 \mathrm{E}-5$ \\
$4-4-2$ & $2.3 \mathrm{E}-2$ & $1.3 \mathrm{E}-5$ & $1.2 \mathrm{E}-5$ & $5.9 \mathrm{E}-4$ & $1.1 \mathrm{E}-2$ & $1.6 \mathrm{E}-5$ & $6.3 \mathrm{E}-5$ \\
$4-1-1$ & $3.3 \mathrm{E}-2$ & $6.6 \mathrm{E}-7$ & $<4 \mathrm{E}-7$ & $2.4 \mathrm{E}-4$ & & $1.7 \mathrm{E}-6$ & $1.3 \mathrm{E}-5$ \\
$1-3-1$ & $3.6 \mathrm{E}-3$ & $1.4 \mathrm{E}-4$ & $5.4 \mathrm{E}-6$ & $6.3 \mathrm{E}-3$ & $8.6 \mathrm{E}-3$ & $2.6 \mathrm{E}-3$ & $2.0 \mathrm{E}-5$ \\
\hline
\end{tabular}

Shaded rows indicate compacts known to have one or more particles with failed $\mathrm{SiC}$. Note that a fraction of 2.4E-4 corresponds to the equivalent inventory of a single particle.

Three of the compacts in Table 4 were found to have one or more particles with failed $\mathrm{SiC}$, as discussed further below. These compacts are shaded in the table. In the case of Compacts 5-2-3 and 5-2-1, the particles with failed $\mathrm{SiC}$ were first identified using particle gamma counting following the pre-burn leaching steps and removed from the population prior to burn-leach analysis, therefore the kernels of these particles were not leached during that analysis. Compact 6-3-2 contained a single particle with failed $\mathrm{SiC}$, and this particle remained in the population when burn-leach was performed. As a result, the contents of this kernel were dissolved in the burnleach solutions and are included in the totals in Table 4 (note the inventory of ${ }^{238} \mathrm{U}$ for Compact 6-3-2, which is close to the equivalent fraction of a single particle, $2.4 \times 10^{-4}$, indicating that the kernel was dissolved in the leach solution). Therefore the values in this table for Compact 6-3-2 that are at or below a value of approximately $2.4 \times 10^{-4}$ (including ${ }^{110 \mathrm{~m}} \mathrm{Ag},{ }^{144} \mathrm{Ce}$, and ${ }^{134} \mathrm{Cs}$ ) are not a reliable measure of the inventory retained in this compact outside of the $\mathrm{SiC}$ layer because of the additional contribution from the kernel leached during the post-burn leach.

The data in Table 3 and Table 4 are summarized graphically in Fig. 2, which indicates the range of fractional fission product inventory retained in the compacts outside the $\mathrm{SiC}$ layer (red columns) and released from the 12 compacts in each capsule (blue columns). In Fig. 2, the separate upper data ranges for ${ }^{134} \mathrm{Cs}$ (circled in the figure) are attributed to compacts or capsules containing particles with failed $\mathrm{SiC}$ layers, while the lower data ranges are due to fuel with only intact $\mathrm{SiC}$ (discussed further below). The cross-hatched regions of several of the data columns indicate that the measured inventories on some capsule components were below the detection limit of the technique, and the sum of contributions from all components therefore represents a conservative upper bound for the total inventory in several of the capsules.

The estimated fraction of ${ }^{110 \mathrm{~m}} \mathrm{Ag}$ retained in 56 of the 72 AGR-1 compacts at the end of irradiation is shown in Fig. 3. This was determined from the fuel compact gamma scanning data, with the total measured inventory for each compact compared to the predicted inventory from physics simulations. The data are plotted as a function of the vertical position in the AGR-1 test train, with the top of the test train at the left, and compacts in each of the three fuel stacks plotted separately. Note that the fraction slightly exceeds 1.0 (the maximum value is 1.09) for several compacts in Capsules 2,3, and 4. This could be due to uncertainties in the gamma spectra analysis (total uncertainty in the final values is estimated to be approximately 5\%), a small bias in the predicted ${ }^{110 \mathrm{~m}} \mathrm{Ag}$ inventories from the physics simulation (in this case the implication is that predicted values could be biased low), or a combination of both. 


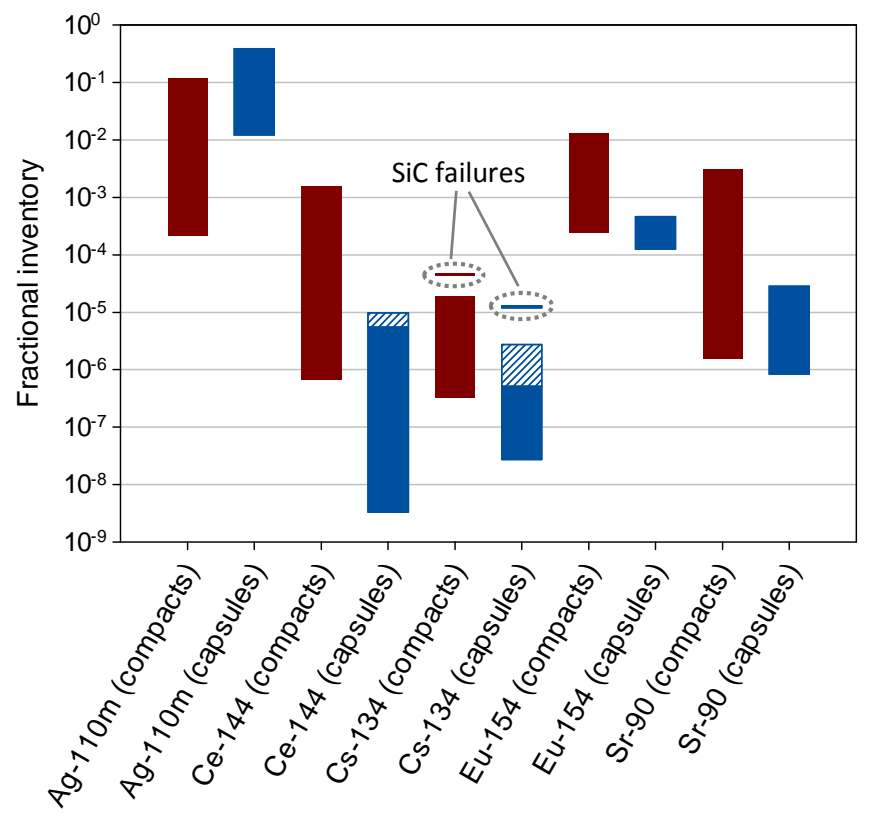

Fig. 2. The range of inventory fractions found retained in irradiated compacts outside of the $\mathrm{SiC}$ layer (red columns) and on the capsule components (blue columns). The portions of the data circled and labeled as "SiC failures" are related to the presence of particles with failed SiC layers, as discussed in the text. The cross-hatched regions indicate values that correspond to measured inventories below the detection limit, and therefore represent a conservative upper-bound on the range.

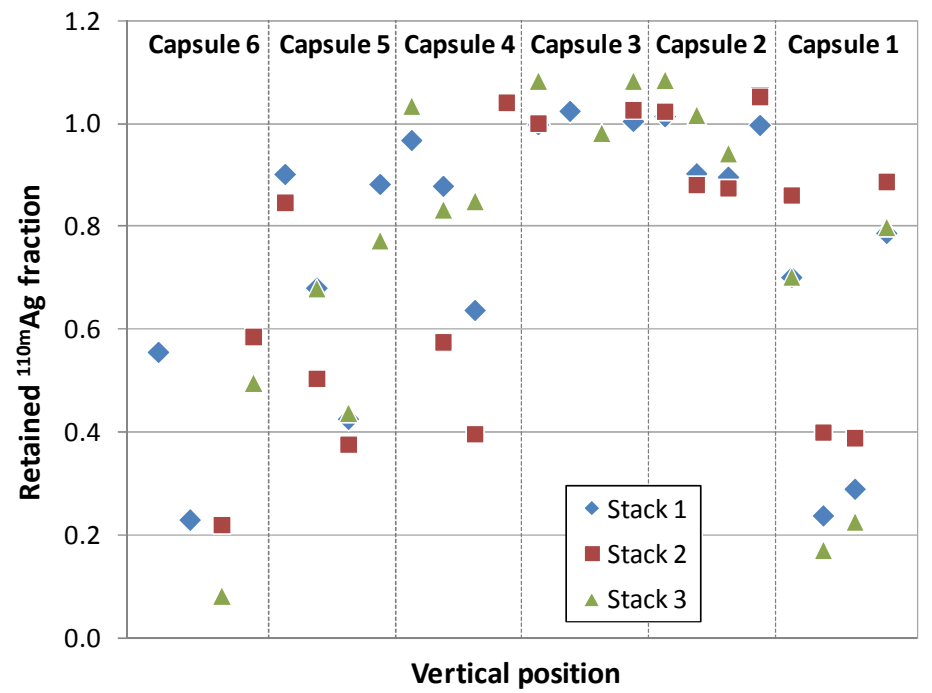

Fig. 3. Fraction of retained ${ }^{110 \mathrm{~m}} \mathrm{Ag}$ inventory in 56 of the 72 AGR-1 fuel compacts after irradiation. Data are plotted as a function of vertical position in the experiment (top of the experiment at the left) and by the stack number.

The fraction of ${ }^{110 \mathrm{~m}} \mathrm{Ag}$ retained in individual particles often varied considerably within a single compact. The distributions of ${ }^{110 \mathrm{~m}} \mathrm{Ag}$ fraction retained in particles from several compacts are shown in Fig. 4. In some cases (e.g., Compact 3-2-1), there was a relatively high degree of silver retention in the sample of particles analyzed (mean of the distribution near 1.0). In other cases (e.g., Compact 5-2-3), the distribution was extremely broad, with a portion of the particles exhibiting almost complete release of silver during the irradiation (particles plotted in the zero bin had activities below a quantification limit of $\sim 0.08$ ). The presence of particles in these 
distributions with estimated retained ${ }^{110 \mathrm{~m}} \mathrm{Ag}$ fractions as high as $\sim 1.2$ is believed to be due in part to an appreciable variation in the ${ }^{110 \mathrm{~m}} \mathrm{Ag}$ inventory generated in particles based on their original location within the fuel compacts.

Based on the particle gamma counting data, the average fraction of ${ }^{110 \mathrm{~m}} \mathrm{Ag}$ retained in the subset of particles gamma counted from each compact was determined, and is presented in Table 5. These values represent an estimate for the fraction of ${ }^{110 \mathrm{~m}} \mathrm{Ag}$ retained within the entire population of particles for each compact. For several of the compacts, a number of gamma counted particles did not have detectable ${ }^{110 \mathrm{~m}} \mathrm{Ag}$ activity. In these cases, a minimum detection limit was determined, and was used as an upper bound on the activity of ${ }^{110 \mathrm{~m}} \mathrm{Ag}$ in the particle, while a value of zero was used as the lower bound. The range provided in Table 5 for some of the compacts uses these two bounding values to account for the unknown activity in these particles.
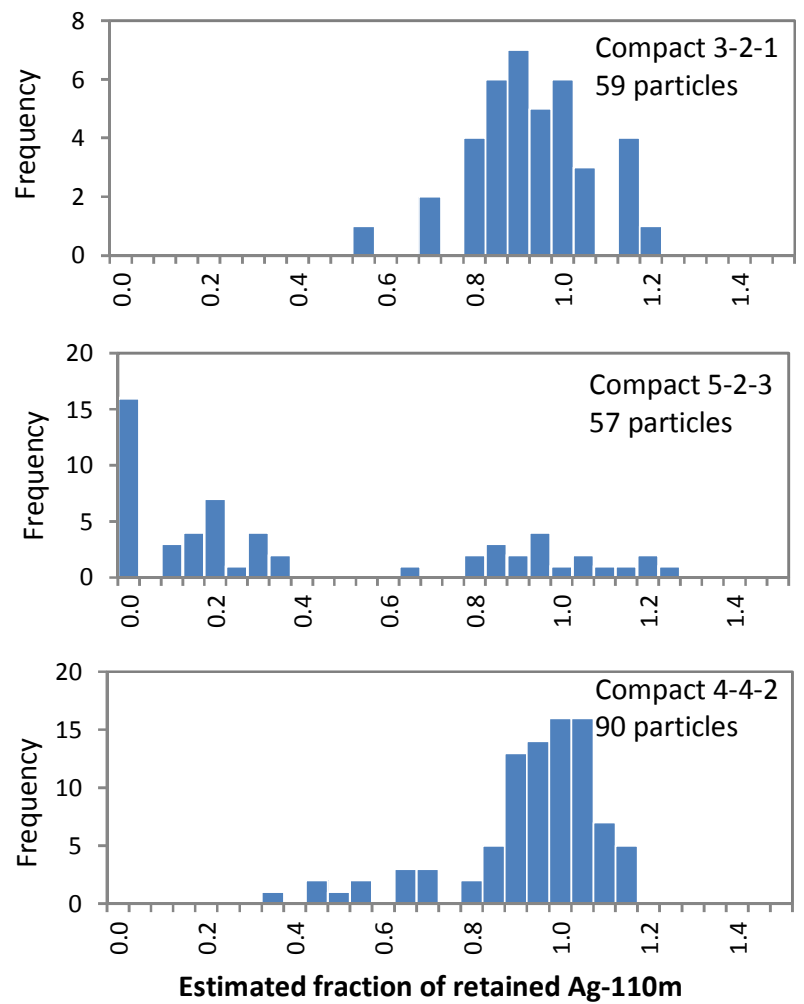

Fig. 4. Distributions for the fraction of ${ }^{110 \mathrm{~m}} \mathrm{Ag}$ retained in particles from three AGR-1 compacts.

Table 5. Average fraction of ${ }^{110 \mathrm{~m}} \mathrm{Ag}$ retained in a sample of particles taken from the irradiated AGR-1 compacts.

\begin{tabular}{cc}
\hline Compact & $\begin{array}{c}\text { Average retained } \\
\text { fraction of }{ }^{110 m} \mathbf{A g}\end{array}$ \\
\hline $6-3-2$ & $0.36-0.51$ \\
$6-1-1$ & $0.39-0.45$ \\
$3-2-1$ & 0.92 \\
$5-2-3$ & $0.43-0.45$ \\
$5-2-1$ & $0.30-0.45$ \\
$5-3-1$ & $0.48-0.57$ \\
$4-4-2$ & 0.93 \\
$4-1-1$ & 1.02 \\
$1-3-1$ & $0.12-0.28$ \\
\hline
\end{tabular}

\subsection{Discussion}

\subsubsection{Cesium}

Past experience with TRISO fuel has demonstrated that the SiC layer provides the primary containment of cesium in the particles, and that cesium release is therefore an effective indicator of SiC failure (Schenk et al., 
1990; Nickel et al., 2002). The total fractional release of ${ }^{134} \mathrm{Cs}$ from the AGR-1 compacts was $<3 \times 10^{-6}$ in Capsules $1-4$ (Table 3), but notably higher in Capsules 5 and $6\left(\sim 10^{-5}\right)$.

Detailed spatial gamma spectrometry of the AGR-1 graphite fuel holders initially identified specific compacts in Capsules 5 and 6 that released higher-than-average quantities of cesium during irradiation (Harp et al., 2012). The identified compacts were the focus of detailed examination to locate and characterize any particles containing a failed $\mathrm{SiC}$ layer that could be responsible for the cesium release. This effort is detailed in a separate paper (Hunn et al., 2014). The results of this analysis have shown that three AGR-1 compacts (two in Capsule 5 and one in Capsule 6) contained particles with failed $\mathrm{SiC}$ and were responsible for a significant portion of the total cesium that was released in those capsules. Compact 5-2-3 contained two such particles while Compact 5-2-1 contained one. All three of these particles were located with the IMGA and detailed analysis has been performed. The level of ${ }^{134} \mathrm{Cs}$ fractional release from these particles ranged from 0.38 to 0.65 , which shows that, while $\mathrm{SiC}$ is the most effective cesium barrier in the TRISO particle, it is not the only defense against cesium release (Hunn et al., 2014). Other analyzed radioisotopes $\left({ }^{95} \mathrm{Zr},{ }^{106} \mathrm{Ru},{ }^{125} \mathrm{Sb},{ }^{144} \mathrm{Ce}\right.$, and ${ }^{154} \mathrm{Eu}$ ) were retained in these three particles within the normal distribution measured by the IMGA on randomly-selected particles with intact $\mathrm{SiC}$. A single particle with failed $\mathrm{SiC}$ was identified in Compact 6-3-2; this particle was identified during DLBL analysis, as evidenced by the level of uranium in the burn-leach solutions (see Table 4), which was equivalent to the inventory in a single kernel.

Based on these results, the total number of particles which experienced failed SiC during the AGR-1 irradiation was determined to be 4 out of approximately $2.98 \times 10^{5}$ particles in the irradiation test, resulting in an in-pile $\mathrm{SiC}$ failure fraction of $1.3 \times 10^{-5}\left(\leq 3.1 \times 10^{-5}\right.$ at $95 \%$ confidence $)$.

Analysis of the AGR-1 cesium data indicates that the majority of cesium released from the fuel compacts in Capsules 5 and 6 originated from the particles with failed SiC. The AGR-1 data also indicate that cesium release from compacts is extremely low in the absence of failed $\mathrm{SiC}\left(<3 \times 10^{-6}\right.$ fractional release from the compacts, based on the data from Capsules $1-4)$. It is concluded that cesium release from the compacts is primarily a function of the number of SiC failures, and detailed study of these particles has been undertaken to better understand the causes of in-pile SiC failure (Hunn et al., 2014).

The level of ${ }^{134} \mathrm{Cs}$ retained outside of the $\mathrm{SiC}$ layer in the compacts (Table 4), was on average slightly higher than the level released from the compacts (see comparison of ${ }^{134} \mathrm{Cs}$ data ranges in Fig. 2). This indicates that there is a certain degree of cesium retention within the compact matrix or OPyC layer. Note that the level of ${ }^{134} \mathrm{Cs}$ released from the compacts to the capsule components in Capsules 5 and 6, and the level found outside of the $\mathrm{SiC}$ layer in Compacts 5-2-3 and 5-2-1, have been plotted separately in Fig. 2, since these levels are due to release from particles with failed $\mathrm{SiC}$, while the values for the remaining capsules and compacts represent release from intact $\mathrm{SiC}$ (with possible contributions from hot cell contamination and uranium contamination in the matrix of the as-fabricated compacts).

\subsubsection{Silver}

The relatively high fractional release of silver is a well-known characteristic of TRISO fuel (Amian and Stöver, 1983; Nabielek et al., 1977). This behavior results from a relatively high rate of transport through SiC and is a strong function of fuel temperature, although other factors, such as the SiC microstructure, likely play a role as well.

Silver release from the AGR-1 particles and compacts was significant in many cases, and exhibited considerable variation. At the capsule level, ${ }^{110 \mathrm{~m}} \mathrm{Ag}$ release fractions ranged from 1.2 to $38 \%$ (Table 3, Fig. 2). Release fractions from individual compacts ranged from approximately $0 \%$ to greater than $90 \%$ (Fig. 3). Within a single compact, silver release from individual particles could also vary considerably, often spanning a range that extended from $100 \%$ retention to near $100 \%$ release, as demonstrated in Fig. 4.

The large range of silver release fractions observed for the AGR-1 particles and compacts is believed to be primarily driven by the temperature of the fuel during irradiation. The effects of temperature-related phenomena, however, are difficult to assess due to the complex nature of the temperature evolution within the fuel compacts as the irradiation progressed. The temperature of the AGR-1 compacts varied considerably with time throughout the irradiation. In the case of compacts with high ${ }^{110 \mathrm{~m}} \mathrm{Ag}$ release, temperatures often achieved relatively high levels for significant portions of the irradiation. For example, computational modeling of temperatures in the AGR-1 fuel (Hawkes, 2012) indicates that in Compact 6-2-3, which exhibited an estimated ${ }^{110 \mathrm{~m}} \mathrm{Ag}$ release of approximately $90 \%$ during the irradiation, roughly half of the fuel particles were at temperatures in excess of $1300^{\circ} \mathrm{C}$ for approximately 100 days.

Another complication encountered when interpreting the thermal history of the fuel compacts is the often significant spatial temperature distributions within individual compacts. Calculation of temperature within the compacts (Hawkes, 2012) indicates that the temperature gradient within an individual compact could often 
exceed $300^{\circ} \mathrm{C}$ at any point in time in many cases, and this could certainly have a profound effect on the distribution of silver release among particles, as demonstrated empirically in the distributions provided in Fig. 4.

Detailed examination of the silver release from compacts and particles as a function of temporal and spatial variation in temperature is still ongoing and is beyond the scope of this paper. Computational modeling of the silver release from compacts, which partially accounts for these temperature variations by using the calculated daily volume-average temperatures for each compact, has resulted in reasonable agreement with the empirical data in Fig. 3 (Collin et al., 2014).

Nonetheless, a key component of the AGR-1 PIE has been to examine various particles based on their observed ${ }^{110 \mathrm{~m}} \mathrm{Ag}$ retention (from particle gamma counting data) in an attempt to correlate silver retention behavior with $\mathrm{SiC}$ layer characteristics, including grain size, grain boundary characteristics, observable $\mathrm{SiC}$ defects (including as-fabricated defects such as carbon soot inclusions), and coating degradation or fractures related to irradiation. The analysis has included non-destructive x-ray imaging, optical microscopy, scanning electron microscopy, and other advanced analytical techniques including transmission electron microscopy, elemental analysis, and atom probe tomography. To date, no clear correlation between $\mathrm{SiC}$ microstructure and the level of ${ }^{110 \mathrm{~m}} \mathrm{Ag}$ retention in the particles has been observed, although statistical data sets for some of these analyses are still relatively small. Therefore the current conclusion is that these variations in ${ }^{110 \mathrm{~m}} \mathrm{Ag}$ release fraction are driven primarily by particle-to-particle temperature variations.

\subsubsection{Strontium}

The strontium inventory retained in the irradiated compacts outside the SiC layer varied considerably (Fig. 2). The upper end of this range $\left(\sim 3 \times 10^{-3}\right)$ is considerably higher than the equivalent inventory from a single particle $\left(2.4 \times 10^{-4}\right)$, and therefore indicates that there was appreciable strontium release through intact particle coatings in certain compacts. The fractional inventory found on the capsule components-representing the release from the compacts-was between approximately $8 \times 10^{-7}$ and $3 \times 10^{-5}$. Comparison of the fraction found outside of the $\mathrm{SiC}$ layer in the compacts with the fraction released from the compacts to the capsules (Fig. 2) indicates that strontium is retained to a significant degree within the surrounding carbonaceous phases of the compact (matrix or OPyC layer).

\subsubsection{Europium}

The europium release behavior was similar to that of strontium, although with the maximum fractional inventory retained in the compacts outside of the $\mathrm{SiC}$ layer and the inventory released from the compacts approximately one order of magnitude higher relative to strontium (Fig. 2). Similar to strontium, these levels (as high as $\sim 10^{-2}$ retained outside of the $\mathrm{SiC}$ layer in the compacts and $\sim 5 \times 10^{-4}$ released from the compacts) indicate appreciable release of europium through intact coating layers. Also similar to strontium, a comparison of the fraction found outside of the $\mathrm{SiC}$ layer in the compacts with the fraction released from the compacts indicates that europium is retained to a significant degree within the carbonaceous phases of the compact (matrix or OPyC layer).

\subsubsection{Cerium}

Cerium behavior was qualitatively similar to that of strontium and europium. Specifically:

(1) The levels outside of the $\mathrm{SiC}$ layers in certain compacts (as high as $1.6 \times 10^{-3}$ ) indicate appreciable release through intact coatings; and

(2) the much higher fraction found in the compacts relative to that released from the compacts indicates significant retention in the carbonaceous phases of the compacts.

The overall fractional inventory retained in the compacts outside the $\mathrm{SiC}$ layer was roughly similar to the corresponding values for strontium. While the maximum fractional release from compacts was similar to that of strontium, in some capsules the release from compacts was much lower (Fig. 2).

\subsubsection{Palladium}

While there are no isotopes of palladium of consequence in terms of radiological hazard, the behavior of palladium in TRISO fuel is of particular interest because of the potential role it can play in SiC layer degradation. The levels of palladium found in the compacts outside of the $\mathrm{SiC}$ layer were relatively high (ranging from approximately 0.6 to $3 \%$, see Table 4), indicating appreciable release through intact coatings. Attempts at 
quantification of palladium on capsule components proved to be largely unsuccessful, and therefore the level of release from the compacts is not known. A key facet of the microanalysis of the irradiated AGR-1 fuel particles was characterization of palladium in the coating layers in order to understand the transport behavior (particularly interaction with and transport through the $\mathrm{SiC}$ layer) and determine the extent to which palladium may play a role in the release of other fission products from the TRISO particles (especially silver). Palladium corrosion was found to be a key contributor to the formation of $\mathrm{SiC}$ failures in particles that released cesium during the AGR-1 irradiation and post-irradiation safety testing (Hunn et al., 2014). The correlation between the distribution of palladium in $\mathrm{SiC}$ and the release of ${ }^{110 \mathrm{~m}} \mathrm{Ag}$ is currently being studied. These effects are discussed below.

\section{KERNEL AND COATING MORPHOLOGY}

A large number of AGR-1 particles have been analyzed microscopically to statistically study changes in kernel and coating morphology induced by irradiation. This includes characterization of almost 1000 particles in fuel compact cross sections, where internal features of each particle were exposed at a single random depth (Ploger et al., 2014). In addition, over 300 loose particles were mounted in planar arrays and examined at multiple elevations for enhanced perspective. Nondestructive x-ray analyses to obtain full three-dimensional insights on select AGR-1 particles have been reported separately (Baldwin et al., 2014; Hunn et al., 2014).

\subsection{Morphological Changes during Irradiation}

The morphology commonly observed within irradiated AGR-1 particles is displayed in Fig. 5. The most conspicuous feature is the radial gap that formed as the buffer shrank away from the IPyC layer during irradiation. However, densification was not complete, because considerably more porosity can be seen in the irradiated buffer than in the dense IPyC and OPyC layers. Approximately $60 \%$ of the particles exhibited complete buffer-IPyC delamination in the planes examined, although thin strips of buffer often remained intermittently attached to the IPyC interior. Only $4 \%$ of the particles revealed intact buffer-IPyC bonding along the entire interface (with the buffer shrinking away from the kernel). In the remaining $36 \%$ of the particles observed, the radial gap was locally interrupted by residual bonding along the buffer-IPyC interface (a somewhat higher percentage was observed in particles examined at multiple levels with better detection of local bonding).

Buffer fracturing occurred in some particles, regardless of the behavior of the buffer-IPyC interface. On average, fractured buffers were found in approximately $22 \%$ of the irradiated AGR-1 particles. On a relative basis, however, fractured buffers were approximately three times more likely in particles with partial buffer-IPyC bonding, such as in Fig. 6, than in particles with either complete delamination or full bonding. This tendency suggests that stress accumulated during delamination where buffer-IPyC bonding was locally strong-at least temporarily-to initiate many buffer fractures.

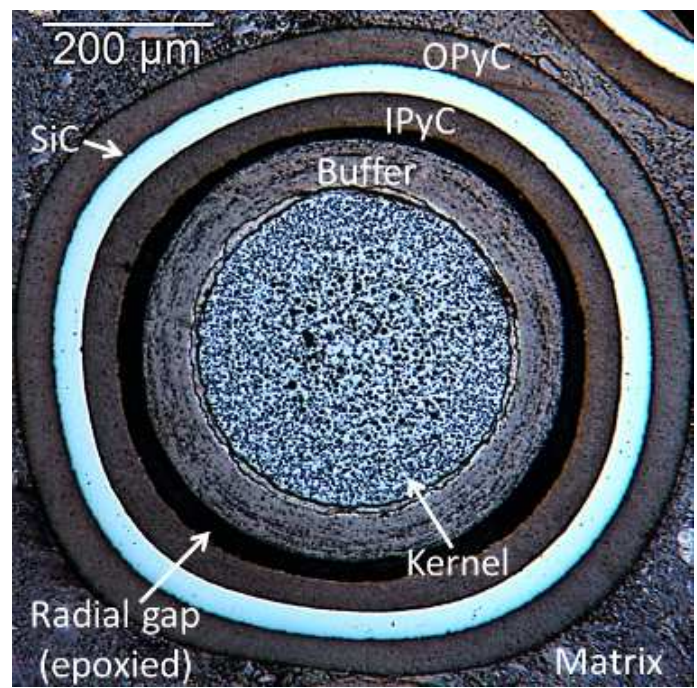

Fig. 5. Irradiated AGR-1 Baseline fuel particle with continuous radial gap from inward shrinkage of the buffer layer.

The kernel frequently protruded into a cavity where the buffer split apart, occasionally approaching the IPyC interior without obviously damaging it. Protrusion was typically more extensive on one side, as in the Fig. 6 
example, presumably where a cavity first opened. This behavior indicates that intact, inwardly shrinking buffers possessed some mechanical strength and constrained kernel growth. Kernels seemed to expand more in the rare particles with no buffer-IPyC delamination due to the outward densification of the buffer. Larger pores tended to be found in kernels with less constrained growth, especially toward the kernel center, as in Fig. 6.



Fig. 6. Irradiated AGR-1 Baseline fuel particle with local buffer-IPyC bonding, buffer fracturing, and protruding kernel.

Despite kernel protrusions, no instances of kernel migration (commonly referred to as the "amoeba effect") were observed in cross-sectioned AGR-1 particles. As seen historically in irradiation testing of uranium dioxide and uranium carbide particles, these kernels can migrate up the temperature gradient into the coating layers (Lindemer and Pearson, 1977). The absence of kernel migration demonstrates that the UCO kernel chemistry effectively reduced the oxygen partial pressure during the AGR-1 experiment.

\subsection{Fractures among TRISO Layers}

Fractures in TRISO layers became progressively less frequent moving outward from the buffer, where $22 \%$ of 1288 total particles analyzed exhibited fracture, to the OPyC layer, where zero fractures were discovered-in agreement with the absence of in-pile fission gas releases. Fractures through the IPyC layer were found in 3\% of the cross-sectioned AGR-1 particles. However, Variant 1 fuel (with a slightly lower average IPyC density due to the higher deposition temperature) contained IPyC fractures in $8.1 \%$ of the particles compared to an average frequency of $1.8 \%$ in particles of all of other fuel types (with higher average IPyC density). Zero fractures through the entire $\mathrm{SiC}$ layer were observed by optical microscopy, but partial thickness cracks were detected in $0.4 \%$ of the $\mathrm{SiC}$ layers.

Fractures among TRISO layers exhibited important relationships. In particles where the buffer-IPyC interface was entirely bonded, the buffers that fractured likely did so as the outwardly densifying buffer came into tension. These fractures propagated directly through the IPyC layer in all eight particles observed, as illustrated in Fig. 7. IPyC-SiC debonding was seen at the "spearhead" tips in six of these cases. In four cases the IPyC-SiC separation induced tangential SiC cracks, although these cracks curved back toward the $\mathrm{SiC}$ interior and did not breach the $\mathrm{SiC}$ layer. In contrast, buffers that shrank inwardly onto the kernel and that fractured after completely delaminating from the IPyC interior could not locally concentrate stress in the IPyC; zero IPyC fractures and $\mathrm{SiC}$ cracks were found in the 98 such particles observed. Thus, complete delamination along the buffer-IPyC interface appears advantageous. 


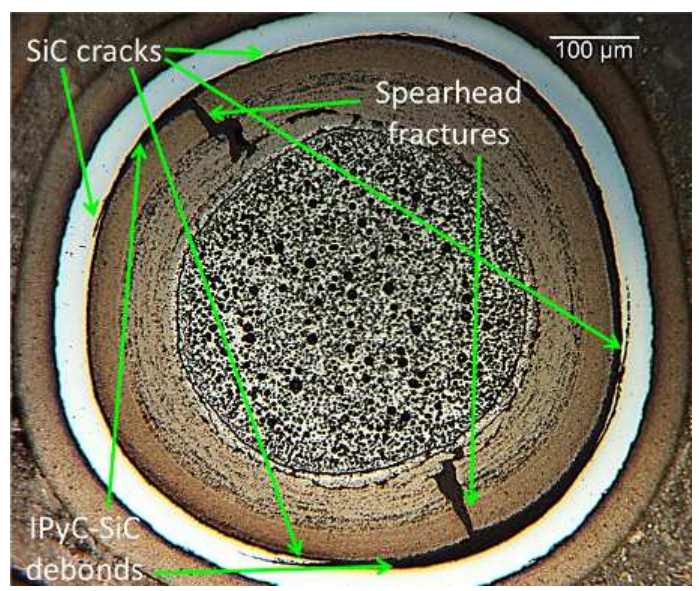

Fig. 7. Irradiated AGR-1 Variant 1 particle, showing aligned buffer-IPyC fractures, IPyC-SiC debonds, and SiC crack formation.

Partial buffer-IPyC delamination did not always protect the IPyC layer from effects of buffer fractures. IPyC fractures were observed in 26 of the 183 particles with both partial delamination and buffer fracturing, and half of these particles revealed IPyC-SiC debonds, as well. However, the buffer fractures and IPyC fractures in such particles were generally not aligned, and the stress patterns when IPyC fractures initiated were often difficult to deduce from end-state configurations. Furthermore, the majority of these IPyC fractures again occurred in Variant 1 fuel particles where the lower density IPyC layer complicates generalization across all AGR-1 fuel types.

Four Variant 1 particles contained IPyC fractures without evident buffer fracture and two of them also had IPyC-SiC debonds. One even revealed $\mathrm{SiC}$ cracks in all six levels examined. As suggested by Fig. 8, buffer shrinkage resulted in delamination along the IPyC interface until positions of strong local bonding were reached. Additional buffer shrinkage then induced fractures through the apparently weak IPyC layer and pulled the IPyC inward, away from the $\mathrm{SiC}$. The IPyC and $\mathrm{SiC}$ then continued to delaminate until tangential $\mathrm{SiC}$ cracks were initiated. These $\mathrm{SiC}$ cracks curved inward and did not breach this key barrier to fission product migration.

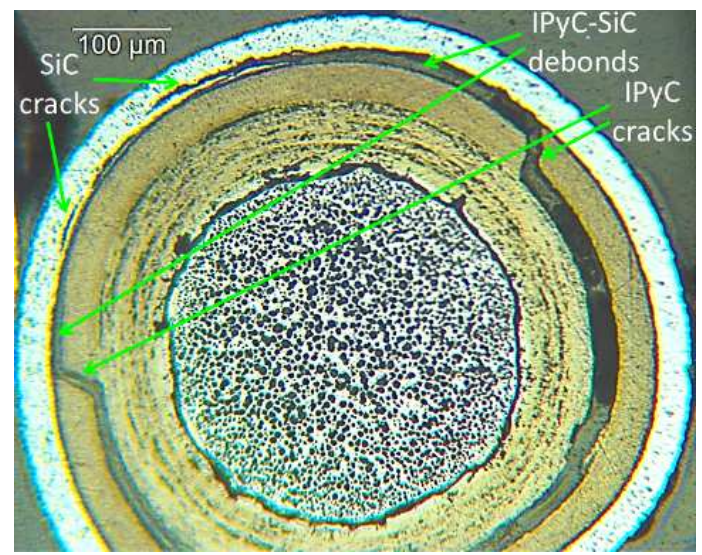

Fig. 8. Irradiated AGR-1 Variant 1 particle, showing IPyC fracturing, IPyC-SiC delamination, and SiC crack formation without buffer fracturing.

Detailed analysis of particles that have experienced a failure of the $\mathrm{SiC}$ layer-both during irradiation and during post-irradiation safety testing - has indicated that fracture of the IPyC and delamination at the IPyC-SiC interface were the most frequently observed coating morphologies, with $\mathrm{SiC}$ damage occurring in the region where the $\mathrm{SiC}$ had been exposed and palladium was allowed to concentrate (Hunn et al., 2014). Thus one of the key findings of this study is that complete and rapid delamination at the buffer-IPyC interface is preferred in order to avoid subsequent consequences of IPyC fracturing and IPyC-SiC delamination, which can preferentially lead to $\mathrm{SiC}$ failure.

\section{MICROANALYSIS OF FISSION PRODUCTS IN IRRADIATED PARTICLES}


It is common to observe small clusters that contain primarily palladium and uranium within the IPyC and $\mathrm{SiC}$ layer of the AGR-1 fuel using SEM combined with elemental analysis (EDS or WDS), as shown in Fig. 9. However, widespread degradation of the $\mathrm{SiC}$ layer due to reaction with palladium has not been observed in the particles, in spite of peak fuel burnup as high as almost $20 \%$, and temperatures sufficient to induce nearly complete silver release in some particles and compacts

Based on examination of numerous particles, there appears to be a trend in the distribution of these clusters throughout the $\mathrm{SiC}$ layer based on the relative level of silver release from the particles. In particles with relatively high silver release, the clusters are found through the entire thickness of the SiC layer, while in particles with relatively low silver release they are found only in approximately the inner half of the SiC thickness (Gerczak et al., 2014).

A concerted effort has been undertaken to identify all of the fission products present in the precipitate clusters that were identified in the SiC layer using SEM elemental analysis, TEM-EDS, and TEM-selected area diffraction (SAD) patterns. These initial examinations revealed that the majority of the precipitates consisted mainly of $\mathrm{Pd}, \mathrm{U}$, and $\mathrm{Si}$, with the $\mathrm{SAD}$ patterns corresponding to a structure similar to that of $\mathrm{UPd}_{2} \mathrm{Si}_{2}$. However the proportions of $\mathrm{U}$ and $\mathrm{Pd}$ did not match this stoichiometric composition. The composition of these precipitates could vary and in some cases small quantities of other fission products (including $\mathrm{Cs}, \mathrm{Zr}$ and $\mathrm{Ce}$ ) were identified (van Rooyen et al., 2014a). Examples of the Pd-rich precipitates found at the IPyC-SiC interface in a particle from Compact 6-3-2 are shown in Fig. 10 (light-colored regions).

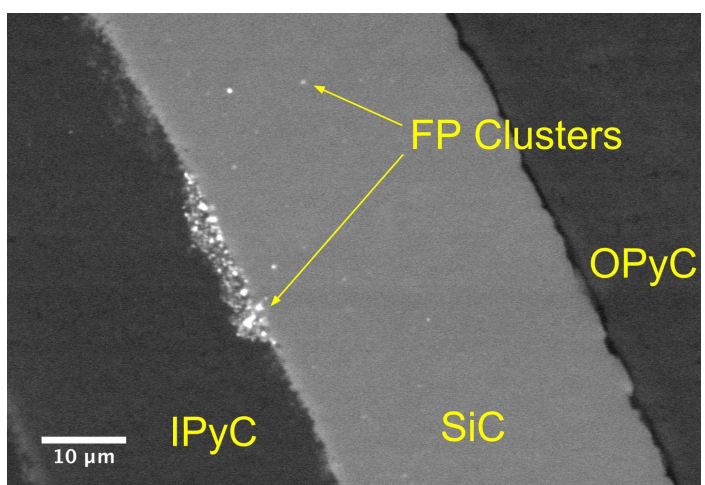

Fig. 9. Backscatter electron micrograph of TRISO layers from a Compact 5-2-1 particle exhibiting low ${ }^{110 \mathrm{~m}} \mathrm{Ag}$ retention, indicating fission product pile-up at $\mathrm{IPyC} / \mathrm{SiC}$ interface and cluster distribution in $\mathrm{SiC}$.

Additional analysis has been performed to explore these precipitates at the nanometer and atomic scales. In particular, the presence of silver in the $\mathrm{SiC}$ microstructure has been explored in order to better understand its transport behavior. The first direct evidence of silver in the SiC layer of irradiated TRISO-coated particles was obtained using STEM, EELS and energy-filtered transmission electron microscopy (EFTEM). Nano-sized ( 2-5 $\mathrm{nm}$ ) silver precipitates were identified in $\mathrm{SiC}$ grain boundaries and triple points at the edge of the $\mathrm{SiC}-\mathrm{IPyC}$ interface up to a depth of approximately $0.5 \mu \mathrm{m}$ (Fig. 11), and in the $\mathrm{SiC}$ layer to a distance of approximately 13 $\mu \mathrm{m}$ from the IPyC-SiC interface. No silver was identified within the $\mathrm{SiC}$ grains. While cadmium was also found in the triple junctions where silver was identified, no palladium was found in these triple junctions (van Rooyen et al., 2014b); however, separate high resolution transmission electron microscopy (HRTEM) examination of the $\mathrm{SiC}$ layer in another AGR-1 particle has identified cadmium, silver, and palladium at the same location (van Rooyen et al., 2014c). Characterization of the coating layers of irradiated AGR-1 particles is continuing, in order to better correlate the observations of fission products in the layers with irradiation conditions, SiC microstructure, and the overall level of fission product release from the particle. 


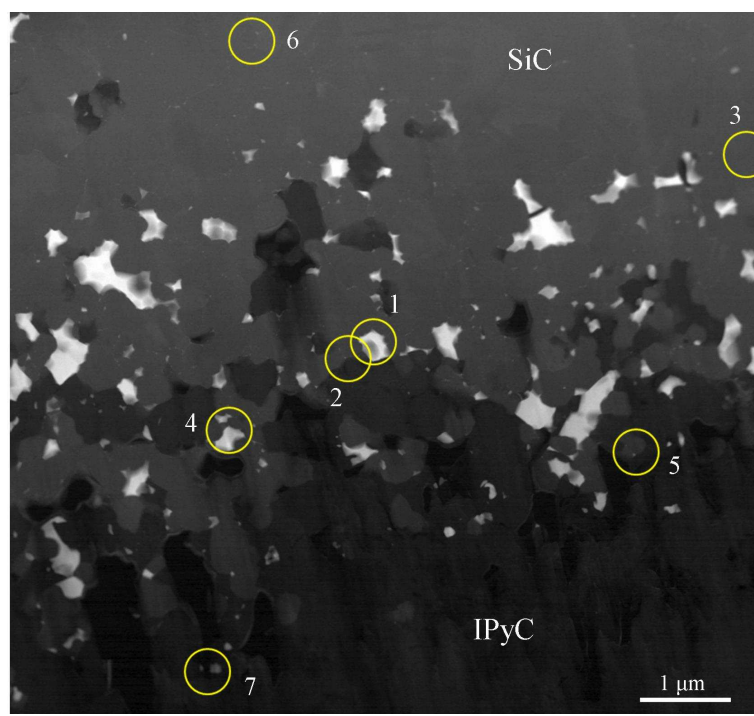

Fig. 10. STEM Z-contrast micrograph using the high-angle annular dark-filed (HAADF) detector showing the three main examination areas: the SiC-IPyC interlayer (numbers 1 to 5), deeper inside the SiC layer (number 6) and the IPyC layer further away from the SiC-IPyC interlayer (number 7). Specimen taken from AGR-1 Compact 6-3-2.

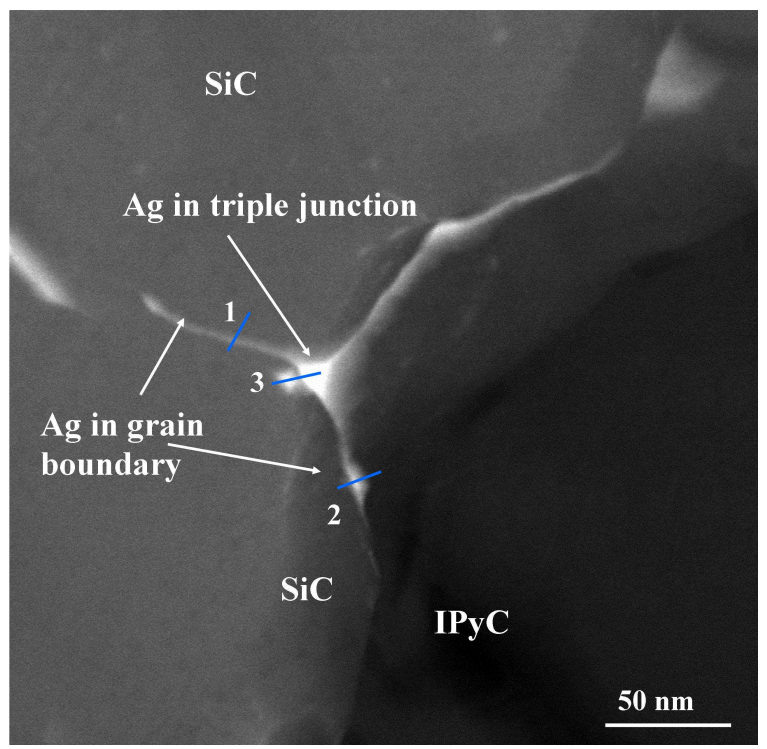

Fig. 11. Image showing the HAADF STEM image of grain boundaries and a triple junction at the SiC-IPyC interface (at area 2 shown in Fig. 10) containing silver (van Rooyen et al., 2014b).

\section{CONCLUSIONS}

Extensive PIE on the AGR-1 irradiation capsules, fuel compacts, and fuel particles has been completed in order to better understand the irradiation performance of the fuel with respect to fission product release and coating behavior. The fuel performed well to a peak burnup of nearly $20 \%$ FIMA. Zero TRISO failures were observed during the irradiation, and PIE indicated that the observed SiC failure fraction was $1.3 \times 10^{-5}$.

Data on the release of metallic fission products was collected using a number of experimental methods. The behavior of specific elements is summarized below.

Cesium. Release was very low from compacts containing only particles with intact SiC (fractional release of ${ }^{134} \mathrm{Cs}$ was $<3 \times 10^{-6}$ in four of the AGR-1 capsules). A total of four particles were identified in the test train that experienced $\mathrm{SiC}$ failure in-pile, releasing appreciable cesium inventory, and resulting in fractional release in the remaining two capsules of approximately $10^{-5}$.

Silver. Fractional release of ${ }^{110 \mathrm{~m}} \mathrm{Ag}$ from individual compacts ranged from approximately 0 to 0.9 . Fractional release from particles within a compact could vary considerably, depending on the compact. These wide 
variations in behavior are most likely due primarily to the temperature history of the compacts and individual particles during the irradiation. At the capsule level, the average fractional release from the compacts ranged from approximately 0.01 to 0.38 .

Strontium. Released in small amounts through intact TRISO coatings, but largely retained within the compacts outside of the $\mathrm{SiC}$ layer. Average fractional release of ${ }^{90} \mathrm{Sr}$ from the compacts ranged from approximately $8 \times 10^{-7}$ to $3 \times 10^{-5}$.

Europium. Generally similar behavior to strontium, but maximum levels of release were roughly an order of magnitude higher. Average fractional release of ${ }^{154} \mathrm{Eu}$ from the compacts ranged from approximately $1 \times 10^{-4}$ to $5 \times 10^{-4}$.

Cerium. Generally similar behavior to strontium and europium. The maximum levels of release were roughly similar to those of strontium. Average release of ${ }^{144} \mathrm{Ce}$ from the compacts was $<10^{-5}$ in all capsules.

Palladium. Palladium was clearly transported through intact $\mathrm{SiC}$, as evidenced by DLBL analysis and microstructural observation. The fractional inventory of ${ }^{105} \mathrm{Pd}$ released from the particles but retained in the compacts outside of the SiC layer was approximately $6 \times 10^{-3}$ to $3 \times 10^{-2}$, based on analysis of 6 irradiated compacts.

Microanalysis of the irradiated particles has indicated that delamination of the buffer and IPyC layers appears to be the preferred coating evolution during irradiation. Persistent bonding of the buffer and IPyC layers can in isolated cases place sufficient stresses on the IPyC layer to induce fractures and delamination from the SiC layer, which in turn can result in $\mathrm{SiC}$ coating damage. The IPyC layer in Variant 1 fuel was more prone to fracturing compared to the other fuel types. In addition, based on the morphology of irradiated kernels, it is clear that the UCO fuel is effectively controlling oxygen partial pressure in the fuel and preventing kernel migration.

Fission products, most notably palladium, have been found diffusing through the SiC layer in the irradiated particles, although widespread degradation of the $\mathrm{SiC}$ layer by palladium has not been observed. Uranium is also often found in conjunction with palladium in the $\mathrm{SiC}$ layer. Traces of silver and other key fission products (e.g., $\mathrm{Cd}, \mathrm{Ce}$, and $\mathrm{Zr}$ ) have been found in some of these precipitates at the $\mathrm{SiC}$ grain boundaries, providing new insights into fission product transport mechanisms.

\section{ACKNOWLEDGEMENTS}

This work was supported by the U.S. Department of Energy, Office of Nuclear Energy, under the Very High Temperature Reactor Technology Development Office Advanced Gas Reactor Fuel Development and Qualification Program. 